\title{
Cerebral oxygenation and bioelectrical activity in preterm infants during surfactant replacement therapy with porcine and bovine preparations
}

\author{
Tomasz Szczapa ${ }^{1}$, Łukasz Karpiński ${ }^{2}$, Hanna Szczapa-Krenz ${ }^{1}$, Beata Witosław ${ }^{1}$, \\ Aleksandra Adamczak ${ }^{1}$, Jerzy Moczko ${ }^{3}$, Izabela Miechowicz ${ }^{3}$, Paweł Niedbalski , \\ Marta Szymankiewicz-Bręborowicz ${ }^{1}$, Jan Mazela ${ }^{2}$
}

\author{
${ }^{1}$ Department of Neonatology, Neonatal Biophysical Monitoring and Cardiopulmonary \\ Therapies Research Unit, Poznan University of Medical Sciences, Poznan, Poland \\ 2Department of Neonatal Infectious Diseases, Poznan University of Medical Sciences, \\ Poznan, Poland \\ ${ }^{3}$ Department of Computer Science and Statistics, Poznan University of Medical \\ Sciences, Poznan, Poland \\ ${ }^{4}$ Elmiko, Warsaw, Poland
}

Submitted: 3 March 2020; Accepted: 28 April 2020

Online publication: 25 June 2020

Arch Med Sci 2022; 18 (3): 652-658

DOI: https://doi.org/10.5114/aoms.2020.96722

Copyright (c) 2020 Termedia \& Banach

\section{Abstract}

Introduction: Surfactant replacement therapy (SRT) might cause acute changes in cerebral oxygenation and alteration of brain bioelectrical activity. Varying physiologic responses and clinical outcomes were observed when different surfactant preparations were instilled to treat neonatal respiratory distress syndrome (RDS).

Material and methods: Neonates born at 26-30 weeks of gestation with RDS requiring intubation and mechanical ventilation were randomized to SRT either with poractant alfa (A) or beractant (B). Saturation $\left(\mathrm{SpO}_{2}\right)$, heart rate $(\mathrm{HR})$, cerebral tissue oxygenation $\left(\mathrm{StO}_{2}\right)$ and amplitude-integrated electroencephalography (aEEG) were simultaneously recorded prior to and up to $4 \mathrm{~h}$ after SRT.

Results: Mean $\mathrm{SpO}_{2}, \mathrm{HR}$ and $\mathrm{StO}_{2}$ values were comparable between groups at baseline and after SRT. There were differences in mean aEEG voltage before SRT, but amplitudes were within a range considered as normal in both groups. Immediately after SRT and at a few single post-intervention time points mean aEEG voltage was higher in the beractant group. There was a significant difference in the percentage of time with the aEEG signal $<5 \mu \mathrm{V}$ after SRT between groups (mean $25.7 \%$ (A) vs. $16.5 \%$ (B), $p<0.05$ ). Quantity of bursts per minute and mean length of inter-burst intervals (IBI) in the aEEG recording varied insignificantly but there was a significant difference in the percentage of $|\mathrm{B}|>30 \mathrm{~s}$ between groups (52.5\% (A) vs. $36.6 \%$ (B), $p<0.05)$.

Conclusions: This is the first study assessing brain bioelectrical function and oxygenation while using two different surfactant preparations in a neonate. Cerebral effects of SRT are observed regardless of the type of surfactant, but their magnitude may depend on the preparation and/or dosing used.

Key words: surfactant, cerebral oxygenation, amplitude-integrated electroencephalography, newborn, preterm infant.

\section{Corresponding author:}

Tomasz Szczapa MD, PhD

Department of Neonatology Neonatal Biophysical

Monitoring and

Cardiopulmonary Therapies

Research Unit

Poznan University

of Medical Sciences

33 Polna St

60-535 Poznan, Poland

Phone: +48618419270

E-mail: tszczapa@gmail.com 


\section{Introduction}

The first successful animal model of surfactant replacement therapy was developed in the 1970s. After tracheal instillation of an animal-derived surfactant extract obtained from lavage of the lungs of mature rabbits directly into the trachea of immature rabbits an improvement in lung mechanics was noted [1]. Ten years later the first successful experience with surfactant replacement therapy in infants with respiratory distress syndrome (RDS) was reported [2]. Administration of animal-derived surfactant became a standard of care in RDS management; however, surfactant preparations differ in their source (bovine vs. porcine), method of extraction (minced vs. lavage), composition (viscosity, phospholipid content, amount of surfactant protein, plasmalogen content), doses, and dosing volumes.

Surfactant deficiency has been suggested as the primary cause of non-invasive respiratory support failure in preterm infants [3, 4]. Despite the clinical benefits, surfactant administration remains an invasive procedure. With a standard approach it requires intubation and may be associated with transient deterioration of patients' condition, e.g. desaturation. It has been shown that surfactant replacement therapy (SRT) may cause acute changes in cerebral oxygenation and suppression of bioelectrical activity measured with amplitude-integrated electroencephalography (aEEG) [5-9]. Varying physiologic responses with different surfactant preparations have been observed in an animal model [9]. There were significant differences in clinical outcome in the comparison trials of bovine vs. porcine surfactants. However, as they were only observed in studies using a higher initial dose of porcine preparation it remains uncertain whether this was caused by the source or dose of the drug $[10,11]$.

The aim of this study was to compare cerebral oxygenation and bioelectrical activity during SRT with porcine and bovine surfactant.

\section{Material and methods}

Preterm infants hospitalized at the Department of Neonatology of Poznan University of Medical Sciences (PUMS) with clinical symptoms of RDS, requiring intubation and mechanical ventilation, with $\mathrm{FiO}_{2}$ requirements $>0.4$ and gestational age (GA) of 26-30 weeks, were included in the study after written parental consent. This was a prospective, randomized, controlled trial approved by the local Institutional Review Board (IRB).

Patients were randomly allocated to one of the treatment groups: SRT with porcine preparation poractant alfa (Curosurf, Chiesi Farmaceutici Parma, Italy), which contains phosphatidylcholine and ap- proximately $1 \%$ surfactant protein (SP) B\&C; $80 \mathrm{mg} /$ $\mathrm{ml}$ phospholipid concentration; given at a dose of $200 \mathrm{mg} / \mathrm{kg}$ in 2 aliquots; or with a bovine preparation - beractant (Survanta; AbbVie Inc., USA), which contains dipalmitoyl phosphatidylcholine, tripalmitin, palmitic acid and less than 0.5\% SP B\&C; 25 $\mathrm{mg} / \mathrm{ml}$ phospholipid concentration; given at a dose of $100 \mathrm{mg} / \mathrm{kg}$ in 4 aliquots [12]. All patients received $20 \mathrm{mg} / \mathrm{kg}$ caffeine citrate intravenously prior to SRT. No premedication was used for endotracheal intubation. All neonates received the surfactant during the first hour of life. Patients were ventilated using pressure-controlled synchronized intermittent mandatory ventilation aiming at tidal volumes of approximately $5 \mathrm{ml} / \mathrm{kg}$. Fraction of inspired oxygen $\left(\mathrm{FiO}_{2}\right)$ was titrated to keep $\mathrm{SpO}_{2}$ within $90-95 \%$. Arterial blood gas analysis (ABG) was performed before and after surfactant administration.

During the study the following parameters were continuously monitored and simultaneously recorded: saturation $\left(\mathrm{SpO}_{2}\right)$ and heart rate $(\mathrm{HR})$ measured with pulse oximetry $\left(\mathrm{SpO}_{2}\right.$ module integrated with aEEG transducer, Nonin, USA), cerebral tissue oxygenation $\left(\mathrm{StO}_{2}\right)$ measured with near-infrared spectroscopy (NIRS) (Invos 5100 oximeter, Medtronic, USA), amplitude-integrated electroencephalography (Neonatal CFM, Elmiko, Poland).

For NIRS measurements a pediatric cerebral sensor was placed on the right side of the forehead. For aEEG monitoring two electrodes, C3-C4, were used. Brain bioelectrical activity was monitored separately from both hemispheres, but for the purpose of the study an averaged aEEG signal was utilized. Dedicated software was used for simultaneous recording of $\mathrm{SpO}_{2}, \mathrm{HR}, \mathrm{StO}_{2}$ and aEEG signals (Elmiko, Poland). Monitoring was initiated 5 min before the procedure and continued for $4 \mathrm{~h}$. Analysis of monitored variables between groups was based on comparison of mean values as well as their relative changes versus baseline.

Additionally, for aEEG percentage of time with low voltage $<5 \mu \mathrm{V}$ and the amount of inter-burst intervals (IBI) were assessed [13]. IBI was defined as an interval $\geq 2$ s that contained no EEG activity above $15 \mu \mathrm{V}[13,14]$. IBI $\geq 30 \mathrm{~s}$ were considered pathological [13-16].

\section{Statistical analysis}

The normality of the data distribution was checked using the Shapiro-Wilk test. For statistical analysis Student's t, Mann-Whitney and Fisher exact tests were used (Statistica 13.3, TIBCO Software Inc.).

\section{Results}

Twenty-four newborns were enrolled in the study and twenty-two were included in the analysis (eleven in each group, Figure 1). Two patients were excluded due to technical issues with signal 


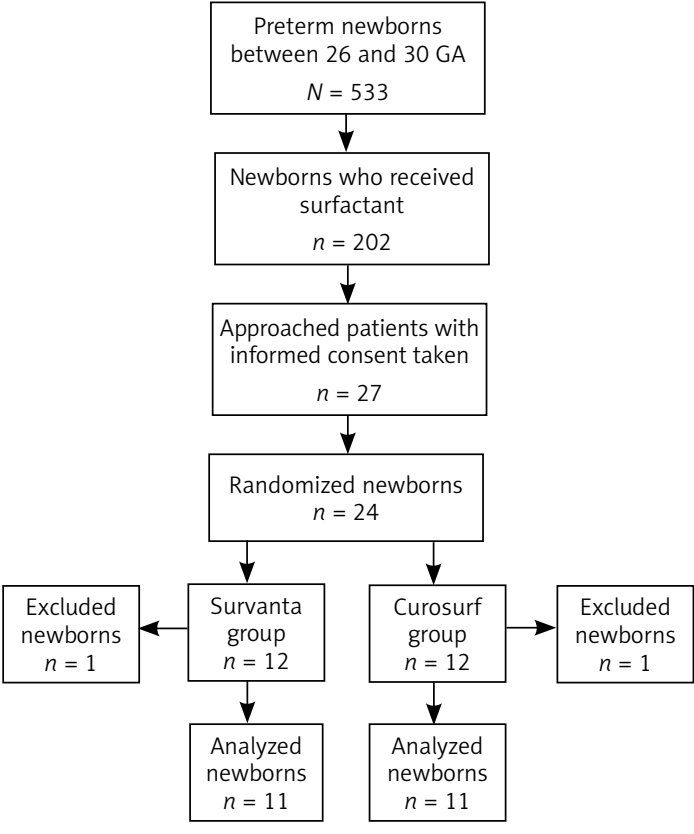

Figure 1. Enrollment flow chart

recordings. There were no significant differences in mean birthweight, GA, and Apgar scores after the first and fifth minute of life, rates of prenatal steroids administration or premature rupture of membranes between groups (Table I).

$\mathrm{FiO}_{2}$ values before and after SRT were similar for both preparations. There were no significant differences between groups in $\mathrm{ABG}, \mathrm{SpO}_{2}, \mathrm{HR}$ and $\mathrm{StO}_{2}$ at baseline. Mean ABG values after the procedure were comparable in patients treated with beractant vs. poractant alfa (Table II). Mean $\mathrm{SpO}_{2}$ during and after SRT was similar in both groups. At selected timepoints there were differences between groups in relative $\mathrm{SpO}_{2}$ changes versus baseline, but they do not seem clinically significant (Figure 2). Mean HR values were similar in both groups,

Table I. Patients' demographic data presented as mean (SD) or percent (\%)

\begin{tabular}{|lccc|}
\hline Parameter & Beractant & Poractant alfa & $P$-value \\
\hline $\begin{array}{l}\text { Gestational } \\
\text { age } \\
\text { [weeks] }\end{array}$ & $27.5(1.2)$ & $27(1.7)$ & ns \\
\hline $\begin{array}{l}\text { Birth } \\
\text { weight [g] }\end{array}$ & $1058(252)$ & $1075(306)$ & ns \\
\hline $\begin{array}{l}\text { Apgar } \\
\text { score 1 }\end{array}$ & $5(2)$ & $6(2)$ & ns \\
\hline $\begin{array}{l}\text { Apgar } \\
\text { score 5 }\end{array}$ & $7(2)$ & $7(1)$ & ns \\
\hline $\begin{array}{l}\text { Prenatal } \\
\text { steroids }\end{array}$ & 73 & 100 & ns \\
\hline PROM & 18 & 18 & ns \\
\hline
\end{tabular}

$S D$ - standard deviation, PROM - premature rupture of membranes, ns - not significant gradually decreasing during the observed period (Figure 3). Mean $\mathrm{StO}_{2}$ did not differ significantly between groups throughout the study (Figure 4). There were differences in mean aEEG voltage before SRT, but amplitudes in both groups were within a range considered as normal $(5-50 \mu \mathrm{V})$ [13]. Immediately after SRT and at a few single time points > $120 \mathrm{~min}$ after intervention mean aEEG voltage was higher in the beractant group (Figure 5). There was a significant difference in the percentage of time with aEEG signal $<5 \mu \mathrm{V}$ after SRT between groups (mean $25.7 \%$ for poractant vs. $16.5 \%$ for beractant, $p<0.05$ ). Quantity of bursts per minute and mean length of inter-burst intervals $(\mathrm{IBI})$ in the aEEG recording varied insignificantly (Table III). There was also a significant difference in the percentage of $|\mathrm{B}|>30 \mathrm{~s}$ between the two groups $(52.5 \%$ for poractant vs. $36.6 \%$ for beractant, $p<0.05)$.

\section{Discussion}

To our knowledge this is the first study to assess brain bioelectrical function (as aEEG) and oxygenation while using two different surfactant preparations in neonates. Beractant and poractant alfa were chosen for this comparison as they are among the most popular formulations and had been compared in previous clinical trials. Reported outcomes included a significant increase in the risk of mortality prior to discharge and death or oxygen requirement at 36 weeks' postmenstrual age in infants treated with modified bovine minced lung surfactant extract compared with porcine minced lung surfactant extract $[10,11,17,18]$.

In the present study patients tolerated both preparations well with no significant differences

Table II. Blood gas analysis and $\mathrm{FiO}_{2}$ results before and after surfactant administration. Data presented as mean (SD)

\begin{tabular}{|lccc|}
\hline Parameter & Beractant & Poractant alfa & $P$-value \\
\hline Before SRT: & & & \\
\hline $\mathrm{FiO}_{2}$ & $0.65(0.22)$ & $0.58(0.24)$ & $\mathrm{ns}$ \\
\hline $\mathrm{pH}$ & $7.27(0.08)$ & $7.25(0.1)$ & $\mathrm{ns}$ \\
\hline $\mathrm{pO}_{2}[\mathrm{~mm} \mathrm{Hg}]$ & $70.36(25.78)$ & $70.14(8.03)$ & $\mathrm{ns}$ \\
\hline $\mathrm{pCO}_{2}[\mathrm{~mm} \mathrm{Hg}]$ & $44.74(10.62)$ & $54.87(19.74)$ & $\mathrm{ns}$ \\
\hline $\mathrm{BE}$ & $-5.95(4.14)$ & $-4.23(1.85)$ & $\mathrm{ns}$ \\
\hline $\mathrm{After} \mathrm{SRT:}$ & $0.28(0.07)$ & $0.24(0.06)$ & $\mathrm{ns}$ \\
\hline $\mathrm{FiO}$ & & & \\
\hline $\mathrm{pH}^{2}$ & $7.27(0.05)$ & $7.31(0.1)$ & $\mathrm{ns}$ \\
\hline $\mathrm{pO}_{2}[\mathrm{~mm} \mathrm{Hg}]$ & $73.99(28.12)$ & $89.76(45.70)$ & $\mathrm{ns}$ \\
\hline $\mathrm{pCO}_{2}[\mathrm{~mm} \mathrm{Hg}]$ & $49.71(7.1)$ & $51.05(19.39)$ & $\mathrm{ns}$ \\
\hline $\mathrm{BE}$ & $-4.15(2.3)$ & $-4.16(2.11)$ & $\mathrm{ns}$ \\
\hline
\end{tabular}

SD - standard deviation, SRT - surfactant replacement therapy, ns - not significant. 
A

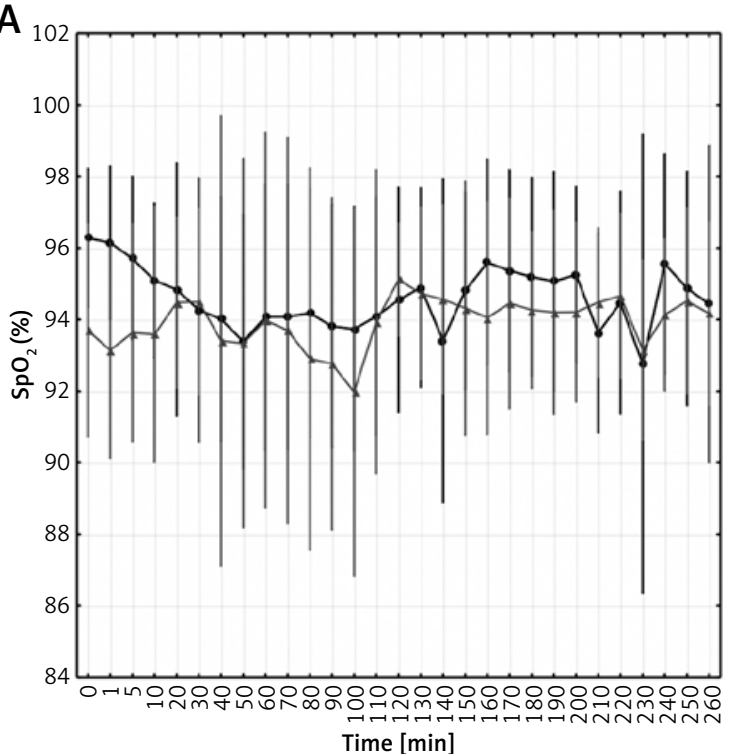

B

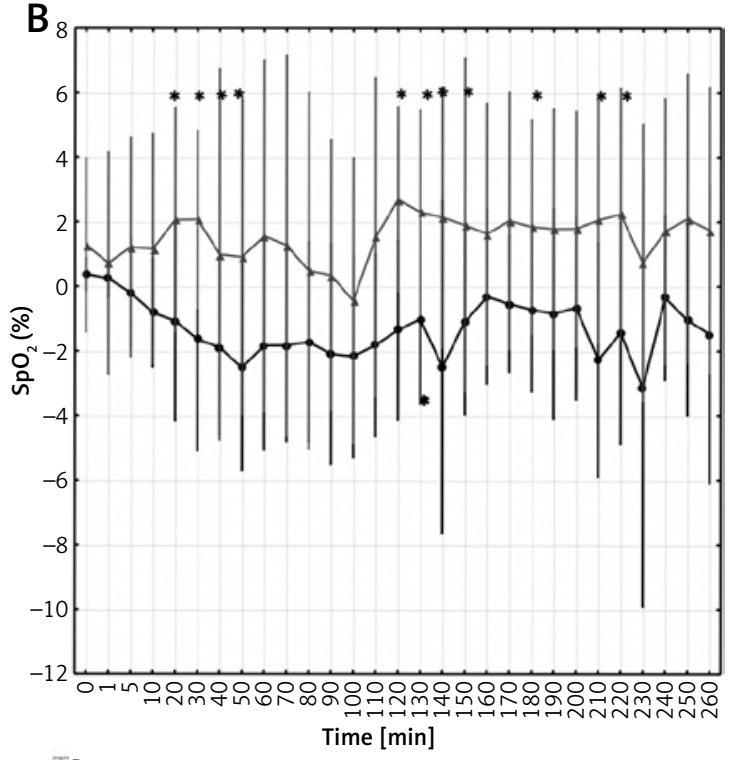

Figure 2. $\mathrm{SpO}_{2}$ before, during, and after surfactant replacement therapy. Values presented as mean (dots) and confidence intervals (vertical lines). A - The graph shows mean values. B - The graph shows delta values after the procedure. Statistically significant changes are marked with $\left(^{*}\right)$

A

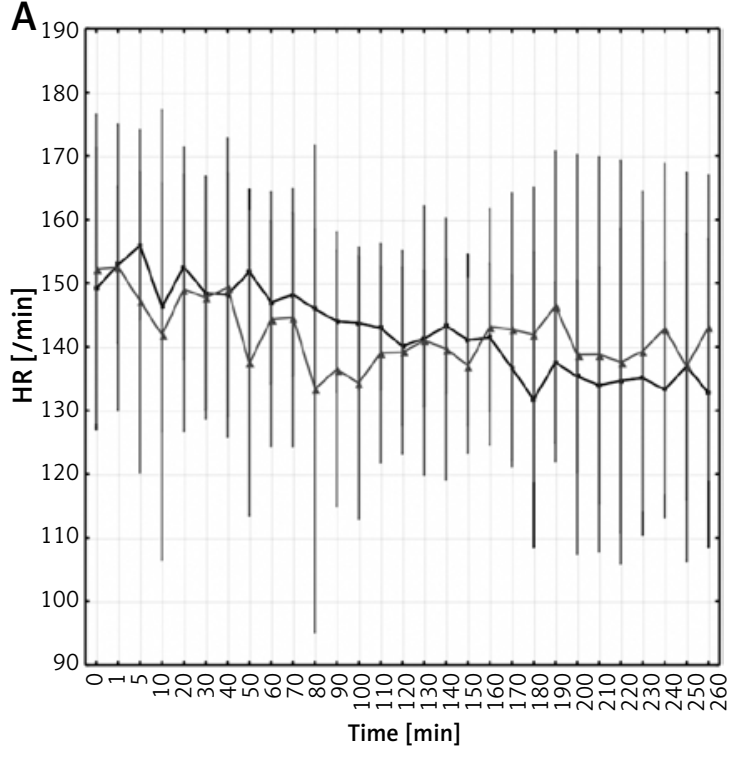

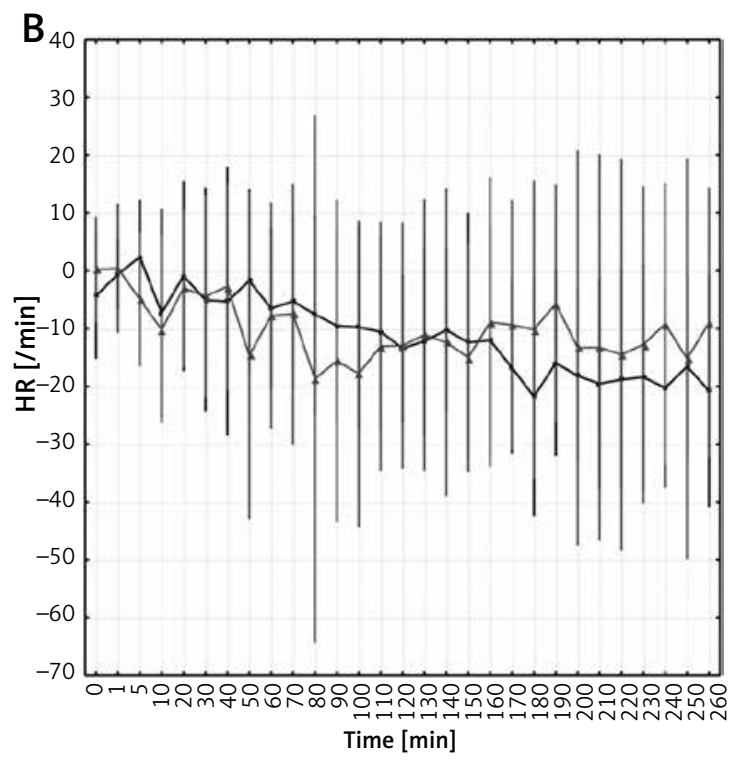

玉poractant 玉Beractant

Figure 3. HR before, during, and after surfactant replacement therapy. Values presented as mean (dots) and confidence intervals (vertical lines). A - The graph shows mean values. B - The graph on the right shows delta values after the procedure. Statistically significant changes are marked with $\left(^{*}\right)$

in $\mathrm{HR}, \mathrm{SpO}_{2}$ or $\mathrm{StO}_{2}$. However, bioelectrical activity of the brain varied between groups. Interestingly, the use of poractant alfa, which has been reported previously to be clinically superior to beractant, led to more pronounced depression of the aEEG signal. Decrease of cerebral activity lasting up to $24 \mathrm{~h}$ despite improvement of pulmonary function after SRT has been reported before with various preparations and techniques of administration [5-8]. One of the proposed mechanisms leading to this phenomenon is a rapid decrease in pulmonary vascular resistance after SRT. Increased left to right shunting via the ductus arteriosus during and after SRT may result in alteration of cerebral blood flow and subsequent changes in bioelectrical activity [7]. Association of hemodynamic fluctuations with EEG alterations have been reported in preterm infants [19].

None of the patients included in the study received premedication; thus it is likely that 
Tomasz Szczapa, Łukasz Karpiński, Hanna Szczapa-Krenz, Beata Witosław, Aleksandra Adamczak, Jerzy Moczko, Izabela Miechowicz, Paweł Niedbalski, Marta Szymankiewicz-Bręborowicz, Jan Mazela
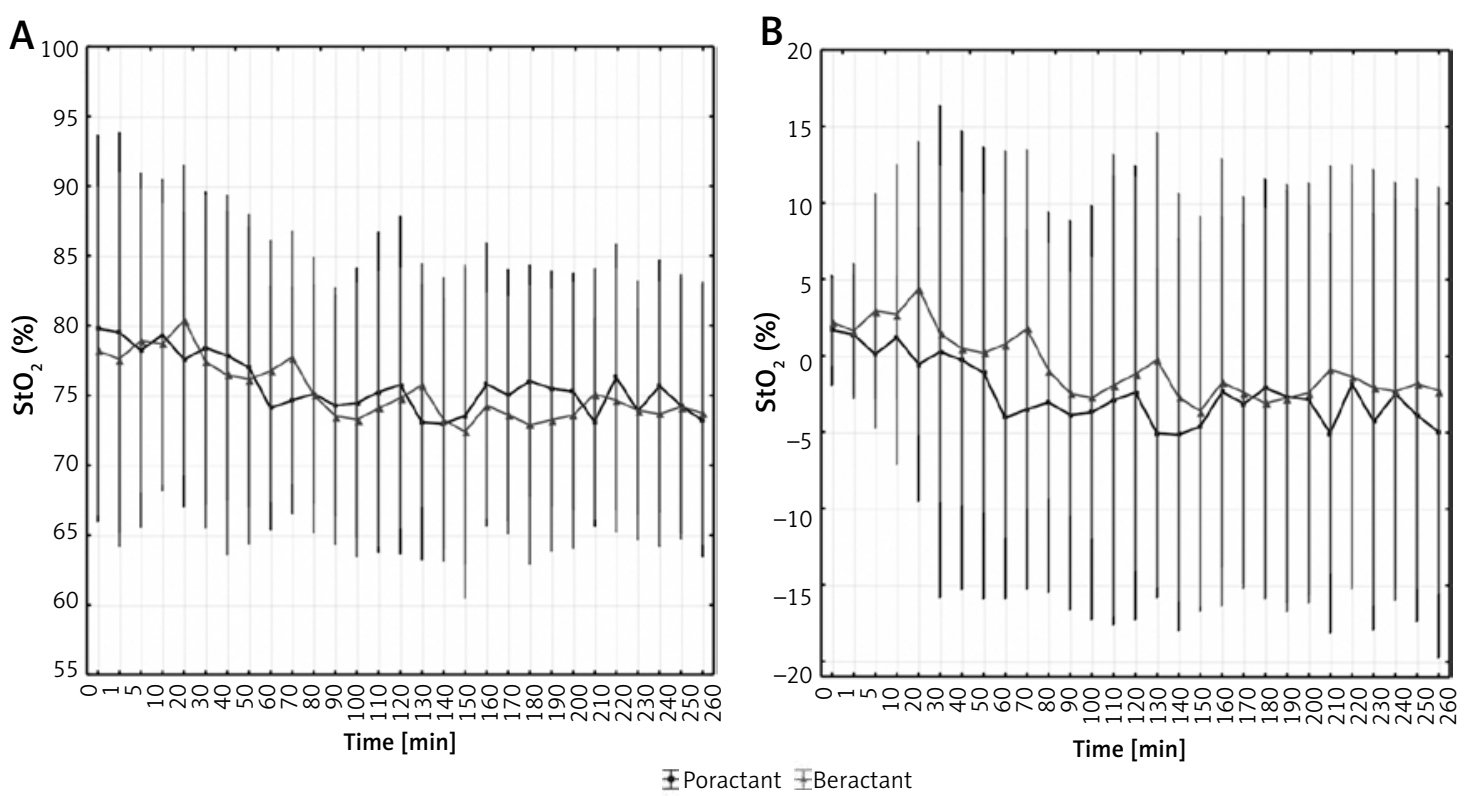

Figure 4. $\mathrm{StO}_{2}$ before, during, and after surfactant replacement therapy. Values presented as mean (dots) and confidence intervals (vertical lines). A - The graph shows mean values. $\mathbf{B}$ - The graph shows delta values after the procedure. Statistically significant changes are marked with $\left(^{*}\right)$

A

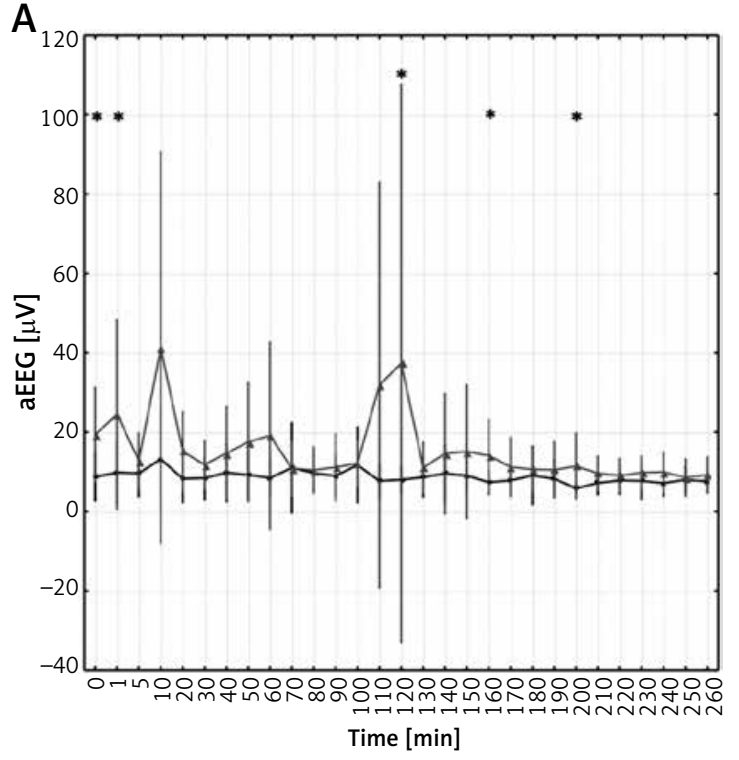

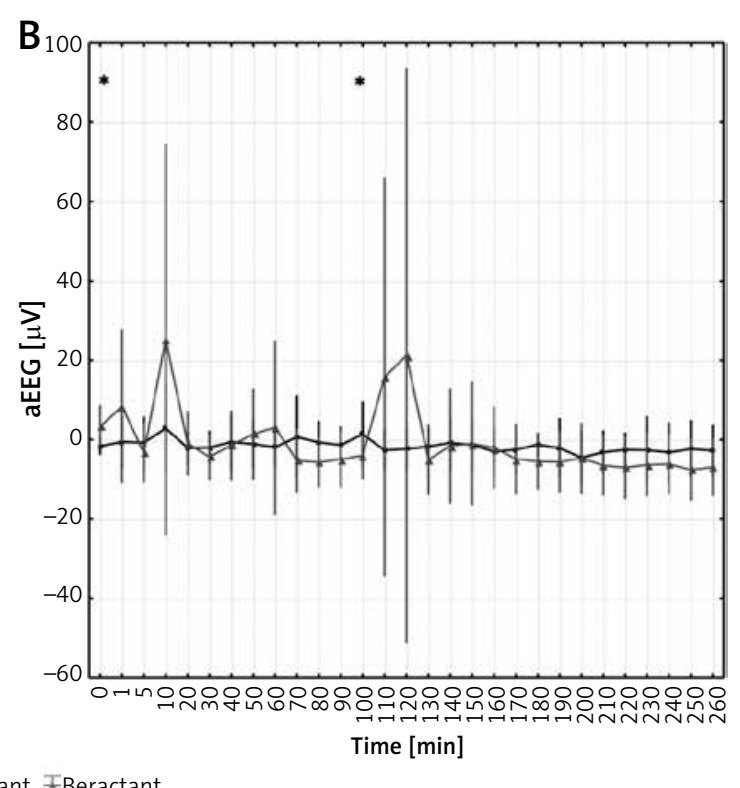

Figure 5. aEEG voltage before, during, and after surfactant replacement therapy. Values presented as mean (dots) and confidence intervals (vertical lines). A - The graph shows mean values. B - The graph shows delta values after the procedure. Statistically significant changes are marked with $\left(^{*}\right)$

observed differences in brain activity between groups were mainly related to differences in surfactant composition and biophysical properties. Poractant alfa in comparison to beractant contains larger amounts of total phospholipids, plasmalogens and polyunsaturated phospholipids, which improves surface activity. There are also significant differences in the surface viscosity between studied preparations. For beractant it was found to rise with decreasing surface tension, while lower surface tensions without an increase in viscosity were observed for poractant [20]. Poractant has been shown to have superior film formation properties in comparison to other preparations [21]. It has been reported that various surfactants markedly differ in their sensitivity to inhibitory plasma proteins (e.g. fibrinogen, albumin and hemoglobin) [22].

Another factor that may be associated with the observed differences in brain activity after SRT is 
Table III. Quantity of bursts per minute and length of inter-burst intervals in the aEEG recording after surfactant replacement therapy. Data presented as mean (SD)

\begin{tabular}{|c|c|c|c|}
\hline Parameter & Beractant & Poractant alfa & $P$-value \\
\hline $\begin{array}{l}\text { Bursts per } \\
\text { minute }\end{array}$ & $2.6(1.2)$ & $1.9(1.1)$ & ns \\
\hline $\begin{array}{l}\text { Length of } \\
\mathrm{IBI}[\mathrm{s}]\end{array}$ & $26(12)$ & $35(11)$ & ns \\
\hline
\end{tabular}

the volume of administered drug. Similar to our study, in which beractant was given at a larger total volume than poractant ( $4 \mathrm{ml} / \mathrm{kg}$ vs. $2.5 \mathrm{ml} / \mathrm{kg}$ ) but with more partial doses (4 vs. 2), Greisen et al. assessed the effects of surfactant administration using two $(1.25 \mathrm{ml} / \mathrm{kg})$ vs. six (approximately $0.42 \mathrm{ml} / \mathrm{kg}$ ) aliquots and found that EEG suppression lasted longer in the latter group despite lack of differences in blood-gas parameters and "more gradual" circulatory changes with more aliquots. No correlations between EEG and cardiopulmonary parameters was found in that study [23]. However, a relationship of aEEG voltage with selected cardiovascular parameters such as superior vena cava flow was described in preterm infants by other authors [24]. It is not certain whether these changes are related directly to dose or perhaps the length of the procedure and less rapid changes in lung mechanics. Mode of administration is another factor that may influence cerebral effects as differences in brain oxygenation were observed between intubated patients and those treated using less invasive surfactant administration $[25,26]$.

Described differences between surfactant preparations can lead to disparate dynamics of response. This may be a potential explanation of observed differences in bioelectrical cerebral activity. In an animal study by Ricci et al. poractant showed superior performance over another bovine preparation (bovactant). Therapy with the porcine drug resulted in more rapid recovery in surfactant deficient rabbits and lambs. Higher oxygenation and ventilation efficiency indices were found for poractant alfa. Higher intrapulmonary gas volumes were also observed in this group [27]. Ventilation efficiency may affect cerebral blood flow, which can further influence EEG activity in preterm neonates [28]. Perhaps more rapid changes of pulmonary function are not equally beneficial for the lung and the brain.

The main limitations of the study include a relatively small sample size and the short time of observation. Although there was a difference in mean aEEG voltage at baseline, these findings should be interpreted with caution. Additionally,
$\mathrm{CO}_{2}$ levels were only monitored using blood gas analysis. Continuous transcutaneous $\mathrm{CO}_{2}$ monitoring might provide more dynamic changes in gas exchange after surfactant administration. Observed changes in bioelectrical baseline activity might also be related to temporary airway occlusion and the aftermath of such a situation and the clinical significance of these findings may be only transient.

Our findings warrant additional studies to investigate the influence of preparation type and dose on neonatal cerebral function and on differences in neurologic outcomes to better understand how surfactant administration may be further optimized.

\section{Conflict of interest}

The authors declare no conflict of interest.

\section{References}

1. Enhorning G, Robertson B, Milne E, Wagner R. Lung expansion in the premature rabbit fetus after tracheal deposition of surfactant. Pediatrics 1972; 50: 58-66.

2. Fujiwara T, Maeta H, Chida S, Morita T, Watabe YJ, Abe T. Artificial surfactant therapy in hyaline membrane disease. Lancet 1980; 8159: 55-9.

3. Gulczyńska E, Szczapa T, Hożejowski R, Borszewska-Kornacka MK, Rutkowska M. Fraction of inspired oxygen as a predictor of CPAP failure in preterm infants with respiratory distress syndrome: a prospective multicenter study. Neonatology 2019; 116: 171-8.

4. Handoka NM, Azzam M, Gobarah A. Predictors of early synchronized non-invasive ventilation failure for infants $<32$ weeks of gestational age with respiratory distress syndrome. Arch Med Sci 2019; 15: 680-7.

5. Hellström-Westas L, Svenningsen NW, Bell AH, Skov L, Greisen G. Cerebroelectrical depression following surfactant treatment in preterm neonates. Pediatrics 1992; 89: 643-7.

6. Skov L, Hellström-Westas L, Jacobsen T, Greisen G, Svenningsen NW. Acute changes in cerebral oxygenation and cerebral blood volume in preterm infants during surfactant treatment. Neuropediatrics 1992; 23: 126-30.

7. Shangle CE, Haas RH, Vaida F, Rich WD, Finer NN. Effects of endotracheal intubation and surfactant on a 3-channel neonatal electroencephalogram. J Pediatr 2012; 161 : 252-7.

8. van den Berg E, Lemmers PM, Toet MC, Klaessens JH, van Bel F. Effect of the "InSurE" procedure on cerebral oxygenation and electrical brain activity of the preterm infant. Arch Dis Child Fetal Neonatal Ed 2010; 95: F53-8.

9. Terry MH, Merritt TA, Harding B, et al. Pulmonary distribution of lucinactant and poractant alfa and their peridosing hemodynamic effects in a preterm lamb model of respiratory distress syndrome. Pediatr Res 2010; 68: 193-8.

10. Ramanathan R, Rasmussen MR, Gerstmann DR, Finer N, Sekar K; North American Study Group. A randomized, multicenter masked comparison trial of poractant alfa (Curosurf) versus beractant (Survanta) in the treatment of respiratory distress syndrome in preterm infants. Am J Perinatol 2004; 21: 109-19. 
Tomasz Szczapa, Łukasz Karpiński, Hanna Szczapa-Krenz, Beata Witosław, Aleksandra Adamczak, Jerzy Moczko, Izabela Miechowicz, Paweł Niedbalski, Marta Szymankiewicz-Bręborowicz, Jan Mazela

11. Singh N, Halliday HL, Stevens TP, Suresh G, Soll R, Rojas-Reyes MX. Comparison of animal-derived surfactants for the prevention and treatment of respiratory distress syndrome in preterm infants. Cochrane Database Syst Rev 2015; 12: CD010249.

12. Fox GF, Sothinathan U. The choice of surfactant for treatment of respiratory distress syndrome in preterm infants: a review of the evidence. Infant 2005; 1: 8-12.

13. Hellström-Westas L, Rosén I, de Vries LS, Greisen G. Amplitude-integrated EEG classification and interpretation in preterm and term infants. NeoReviews 2006; 7: e76-e87.

14. Menache CC, Bourgeois BF, Volpe JJ. Prognostic value of neonatal discontinuous EEG. Pediatr Neurol 2002; 27 93-101.

15. Hahn J, Monyer H, Tharp B. Interburst interval measurements in the EEGs of premature infants with normal neurological values. Encephalogr Clin Neurophisiol 1989; 73: 410-8.

16. Vecchierini MF, Andre M, d'Allest AM. Normal EEG of premature infants born between 24 and 30 weeks gestational age: terminology, definitions and maturation aspects. Neurophysiol Clin 2007; 37: 311-23.

17. Singh N, Hawley KL, Viswanathan K. Efficacy of porcine versus bovine surfactants for preterm newborns with respiratory distress syndrome: systematic review and meta-analysis. Pediatrics 2011; 128: e1588-95.

18. Ramanathan R, Bhatia JJ, Sekar K, Ernst FR. Mortality in preterm infants with respiratory distress syndrome treated with poractant alfa, calfactant or beractant: a retrospective study. J Perinatol 2013; 33: 119-25.

19. West CR, Groves AM, Williams CE, et al. Early low cardiac output is associated with compromised electroencephalographic activity in very preterm infants. Pediatr Res 2006; 59: 610-5.

20. Rüdiger M, Tölle A, Meier W, Rüstow B. Naturally derived commercial surfactants differ in composition of surfactant lipids and in surface viscosity. Am J Physiol Lung Cell Mol Physiol 2005; 288: L379-83.

21. Todorov R, Exerowa D, Platikanov D, Bianco F, Razzetti R. Evaluation of therapeutic pulmonary surfactants by thin liquid film methods. Adv Colloid Interface Sci 2015 ; 222: 709-15.

22. Seeger W, Grube C, Günther A, Schmidt R. Surfactant inhibition by plasma proteins: differential sensitivity of various surfactant preparations. Eur Respir J 1993; 6 : 971-7.

23. Lundstrom KE, Griesen G. Changes in EEG, systemic circulation and blood gas parameters following two or six aliquots of porcine surfactant. Acta Paediatr 1996; 85: 708-12.

24. Shah D, Paradisis M, Bowen JR. Relationship between systemic blood flow, blood pressure, inotropes, and aEEG in first $48 \mathrm{~h}$ of life in extremely preterm infants. Pediatr Res 2013; 74: 314-20.

25. Li XF, Cheng TT, Guan RL, et al. Effects of different surfactant administrations on cerebral autoregulation in preterm infants with respiratory distress syndrome. J Huazhong Univ Sci Technolog Med Sci 2016; 36: 801-5.

26. Bertini G, Coviello C, Gozzini E, et al. Change of cerebral oxygenation during surfactant treatment in preterm infants: "LISA" versus "InSurE" procedures. Neuropediatrics 2017; 48: 98-103.

27. Ricci F, Salomone F, Kuypers E, et al. In vivo evaluation of the acute pulmonary response to poractant alfa and bovactant treatments in lung-lavaged adult rabbits and in preterm lambs with respiratory distress syndrome. Front Pediatr 2017; 5: 186.

28. Greisen G, Pryds O. Low CBF, discontinuous EEG activity, and periventricular brain injury in ill, preterm neonates. Brain Dev 1989; 11: 164-8. 